\title{
Conhecimento dos moradores da comunidade de Boas Novas, no Lago Janauacá - Amazonas, sobre os hábitos alimentares dos peixes da região.
}

\begin{abstract}
Alexandre Milaré BATISTELLA ${ }^{1}$, Carolina Pottër de CASTRO ${ }^{2}$, Julio Daniel do VALE ${ }^{3}$
RESUMO

A pesca na Amazônia é uma das atividades mais antigas e importantes; entretanto a atividade pesqueira tem passado por um rápido processo de modernização. Os moradores da comunidade de Boas Novas, no Lago do Janauacá -AM são, em sua maioria, pescadores-lavradores. No presente trabalho procedeu-se um levantamento de aspectos etnoictiológicos através de entrevistas semi-estruturadas com o objetivo de relacionar a dieta das espécies de peixes citadas na literatura e pelos moradores da comunidade de Boas Novas e a forma com que adquiriram tal conhecimento. Houve correlação de $83 \%$ entre as informações dos pescadores e as encontradas na literatura. A maioria dos informantes adquiriu esse conhecimento através da observação na natureza, do tipo de isca que se usa para cada espécie, tratando os peixes ou informados por outras pessoas; havendo diferenças entre homens e mulheres.
\end{abstract}

PALAVRAS-CHAVES

Amazônia; rio Solimões; Etnozoologia; peixes; dieta.

\section{Regional fish diet knowledge of the Boas Novas community inbabitants on the lake Janauacá - Amazonas, Brazil.}

\begin{abstract}
Fishing in Amazônia is one of the oldest and most important activities; however, fishing has undergone a rapid process of modernization. The formers inhabitants of Boas novas community on the Lake of Janauacá -AM are mostly fisherman. In the present work a recording of ethnoichthyologic aspects was conducted through semi-structured interviews aiming to relate the fish diet mentioned in the literature and by community's inhabitants of Boas Novas, and how they acquired such knowledge. There was a correlation of $83 \%$ between the fishermen information and the literature. Most of the informants acquired their knowledge through observing nature, bait type used for each species, fish with respect to this preparing or information received from other people; there are differences between men and women knowledge.
\end{abstract}

KEYWORDS

Amazon; river Solimões; Ethnozology; fish; diet.

\section{INTRODUÇÃO}

Os conhecimentos das comunidades ribeirinhas sobre os aspectos ecológicos são freqüentemente negligenciados. É preciso reconhecer a existência, entre as sociedades tradicionais, de outras formas, igualmente racionais de se perceber a biodiversidade, além das oferecidas pela ciência moderna (Diegues 2000). Este conhecimento tradicional assegura o acesso rápido a informações elementares para pesquisas cientificas, além de dar subsídios à população local na defesa de "seu lugar".

As comunidades ribeirinhas da Amazônia são compostas em sua grande maioria por moradores que dividem o tempo entre a agricultura e a pesca artesanal, sendo essa a sua maior fonte de proteína animal. Essa pesca é de subsistência, mas eventualmente, a produção excedente é comercializada, principalmente no período de seca. Esses pescadores são

${ }^{1}$ Instituto Nacional de Pesquisas da Amazônia - INPA, Coleção de Anfíbios e Répteis, Av. André Araújo, 2936, CP 478, Petrópoles, 69083 - 000 , Manaus - AM. email nemo@inpa.gov.br, telefone: 926433335

${ }^{2}$ Universidade Estadual do Mato Grosso-UNEMAT, Br 158, Km 148, Cx Postal 08, 78690-000, NovaXavantina-MT. email: tucuxi_br@yahoo.com.br, telefone: 669953 2377 ${ }^{3}$ Instituto Nacional de Pesquisas da Amazônia - INPA, Coordenação de Pesquisas em Ecologia, Av. André Araújo, 2936, CP 478, Petrópoles, 69083 - 000, Manaus-AM. email: juliodv@inpa.gov.br, telefone: 926431833 
usualmente classificados como pescador-lavrador, varjeiro ou polivalente (Petrere, 1992; Furtado, 1993).

O objetivo deste trabalho foi comparar informações dos moradores da comunidade de Boas Novas do lago Janauacá AM e da literatura sobre a dieta das espécies de peixes, além de registrar a origem deste conhecimento.

\section{MATERIAL E MÉTODOS}

O lago Janauacá é característico de várzea, localizado no rio Solimões, no município de Carero Castanho-AM. Esta área foi selecionada para a pesquisa por causa da presença de um assentamento humano representativo de algumas comunidades tradicionais da região no que diz respeito à forma de organização na produção pesqueira.

Na comunidade de Boas Novas há cinqüenta e seis casas de madeira, alvenaria ou flutuantes, localizadas na margem do lago. Há duas igrejas evangélicas e uma escola primária.

A divisão de trabalho na comunidade se dá segundo critérios de sexo e idade; às mulheres, em geral, cabem os tratos caseiros e dos roçados, já a produção da pesca é uma atividade eminentemente masculina (Furtado, 1993). A maioria das famílias, além da pesca, cultivam mandioca para subsistência.

Os dados foram coletados através de entrevistas semiestruturadas com moradores da comunidade de Boas Novas em junho de 2001. Foram visitadas trinta casas da comunidade, sempre com o cuidado de não entrevistar mais de uma pessoa por casa e também não entrevistar alguém que estivesse presente durante outra entrevista, aumentando, assim, o grau de independência das amostras.

Durante a entrevista foi perguntado ao entrevistado quais as espécies de peixes conhecidas por ele, o que esses peixes comem e como o informante adquiriu esse conhecimento.

As espécies citadas foram comparadas com peixes coletados durante o mesmo período por uma equipe do Instituto Nacional de Pesquisas da Amazônia (INPA) e com informações de pesquisadores que trabalhavam na área. Em caso de dúvidas optou-se pela espécie com maior ocorrência na região.

Foram estabelecidas seis categorias de hábitos alimentares: piscívoros, carnívoros, onívoros, iliófogos, planctívoros e herbívoros (modificado a partir de Zavala-Camin, 1996). Dentro destas categorias foram enquadradas as espécies citadas pelos pescadores. Utilizou-se os trabalhos de Santos et al (1984) e Ferreira et al (1998) para comparação literária. O grau de concordância entre os entrevistados e as informações disponíveis em literatura foi verificada através do teste de correlação de Pearson.

Em relação à origem do conhecimento, foi feita a freqüência de ocorrência de cada resposta separando-se por sexo dos entrevistados.

\section{RESULTADOS}

Os dados apresentados na Tabela 1 mostram as quarenta espécies de peixes citadas pelos informantes e a dieta alimentar descrita na literatura e pelos ribeirinhos. O resultado do teste de Correlação de Pearson para comparar o consenso entre pescadores e registros da literatura foi de $83 \%(r=0,914)$.

Verificou-se que há diferença na forma de aprendizagem entre homens e mulheres. Todos os homens entrevistados foram capazes de informar sobre a dieta alimentar dos peixes; todos aprenderam sobre a dieta destes animais através de observação comportamental e pelo tipo de isca que se utiliza para capturá-los; dentre eles $7,1 \%$ informaram que aprenderam também através dos ensinamentos dos mais velhos. Das dezesseis mulheres entrevistadas, 31,25\% aprenderam através de observação ao tratar os peixes; $31,25 \%$ através de observação comportamental e através do tipo de isca utilizada; $31,25 \%$ não sabiam qual era o alimento dos peixes e $6,25 \%$ foram informadas pelos maridos.

\section{DISCUSSÃO}

O valor do teste de correlação mostrou que os pescadores da comunidade de Boas Novas possuem conhecimento consistente e detalhado da dieta alimentar dos peixes por eles capturados. Paz \& Begossi (1996) enfatizam a importância desses resultados, pois reforçam a literatura e podem contribuir para a inclusão de pescadores em decisões de manejo. Poizat \& Baran, (1997) também ressaltam que investigações sobre o conhecimento empírico, acerca da ecologia das espécies locais, deveria ser usado como subsídio para estudos preliminares; constituindo assim, fontes secundária de informação para trabalhos científicos.

Sobre a origem desse conhecimento, há uma diferença marcante na forma como as informações são adquiridas pelos homens e pelas mulheres, evidenciando a distinção de papéis na organização social da comunidade. Sendo o homem o maior responsável pela pesca de consumo, a maioria deles $(92,9 \%)$ conhece o item alimentar de cada peixe pelo contato do dia-a-dia, tanto pela observação ou devido à utilização de isca apropriada para a captura; Marques (1995) afirma que o conhecimento detalhado da ecologia trófica dos peixes se dá porque a inserção correta do item alimentar/isca otimizará o esforço da pesca. Quanto às mulheres, exercem atividades domésticas, tendo menos contato direto com os peixes em ambiente natural, por isso aproximadamente um terço delas não sabia quais eram as fontes de dietas dos peixes, um terço sabe o que determinado peixe come através de observação ao "tratar" o peixe e um terço delas possuía conhecimento da dieta a partir da observação do animal na natureza. Nota-se que o conhecimento de homens e mulheres está fortemente ligado à realidade empírica e à tradição oral, Furtado (1993) ressalta isso, afirmando que os valores das comunidades desses pescadores são fortemente marcados pelo trato com a terra, a pesca e suas associações.

O grau de especificidade de conhecimento é grande, sendo muito ilustrativa uma entrevista em que uma senhora classificou a espécie "mapará" (Hypophtalmus edentatus) como planctívora, utilizando a denominação "ova d'água" para plâncton. 


\section{ACTA AMAZONICA}

A atividade dos pescadores ribeirinhos já foi bastante caracterizada por uma série de autores (Veríssimo, 1895; Goulding, 1983; Petrere, 1992; Furtado, 1993), contudo fica evidente aqui que a direta relação e até mesmo a dependência desse recurso para a sua própria sobrevivência faz com que esses indivíduos consigam desenvolver esse acurado senso de conhecimento da dieta dos principais peixes que consomem. Também ficou estabelecido que o sexo do informante era significativo no levantamento destes dados.

Tabela 1 - Comparação entre a dieta das espécies de peixes (ou grupo de espécies) citadas na literatura e pelos moradores da comunidade de Boas Novas, no Lago Janauacá - Amazonas..

\begin{tabular}{|c|c|c|c|}
\hline \multirow{2}{*}{ Nome popular } & \multirow{2}{*}{ Nome cientifico } & \multicolumn{2}{|c|}{ Dieta } \\
\hline & & Literatura & Informantes \\
\hline Pirarucu & Arapaima gigas & piscívoro & piscívoro \\
\hline Arraia & Potamotrygon sp. & carnívoro & carnívoro \\
\hline Aruanã & Osteoglossum bicirrhosum & onívoro & onívoro \\
\hline Apapá & Pellona castelnaeana & piscívoro & carnívoro \\
\hline Traíra & Hoplias malabaricus & piscívoro & carnívoro \\
\hline Curimatã & Plochilodus nigricans & iliófago & detritívoro \\
\hline Jaraqui & Semaprochilodus spp. & iliófago & detritívoro \\
\hline Branquinha & Curimatidae & iliófago & detritívoro \\
\hline Cubiu & Anodus elongatus & planctívoro & planctívoro \\
\hline Aracu & Schizodon fasciatum & herbívoro & onívoro \\
\hline Tambaqui & Colossoma macropomum & onívoro & onívoro \\
\hline Pirapitinga & Piaractus brachypomus & herbívoro & onívoro \\
\hline Pacu & Mylossoma duriventre & herbívoro & onívoro \\
\hline Piranha & Pygocentrus nattereri & piscívoro & piscívoro \\
\hline Peixe cachorro & Hydrolycus scomberoides & piscívoro & piscívoro \\
\hline Zé-do-ó & Roeboides myersi & carnívoro & carnívoro \\
\hline Matrinxã & Brycon cephalus & onívoro & onívoro \\
\hline Sardinha & Triportheus albus & onívoro & onívoro \\
\hline Bacu & Pterodoras lentiginosus & onívoro & onívoro \\
\hline Tamoata & Hoposternum litoralle & onívoro & detritívoro \\
\hline Bodó & Liposarcus pardalis & iliófago & detritívoro \\
\hline Mapará & Hypophthalmus edentatus & planctívoro & planctívoro \\
\hline Mandubé & Ageneiosus brevifilis & carnívoro & piscívoro \\
\hline Piracatinga & Calophysus macropterus & onívoro & onívoro \\
\hline Cara-de-Gato & Platynematichthys notatus & piscívoro & piscívoro \\
\hline Jandiá & Leiarius marmoratus & carnívoro & onívoro \\
\hline Pirarara & Phractocephalus hemioliopterus & onívoro & carnívoro \\
\hline Dourada & Brachyplatystoma flavicans & piscívoro & piscívoro \\
\hline Pacamum & Paulicea luetkeni & piscívoro & piscívoro \\
\hline Piraíba & Brachyplatystoma filamentosum & piscívoro & piscívoro \\
\hline Piramutaba & Brachyplatystoma vaillanti & piscívoro & piscívoro \\
\hline Sorubim & Pseudoplatystoma fasciatum & piscívoro & carnívoro \\
\hline Mandi & Pimelodus blochii & onívoro & onívoro \\
\hline Caparari & Pseudoplatystoma tigrinum & piscívoro & piscívoro \\
\hline Jacundá & Crenicichla spp. & carnívoro & carnívoro \\
\hline Acará-Açu & Astronotus crassipinnis & onívoro & onívoro \\
\hline Acará-Preta & Heros apendiculatus & onívoro & onívoro \\
\hline Baru & Uaru amphiacanthoides & herbívoro & herbívoro \\
\hline
\end{tabular}




\section{BIBLIOGRAFIA CITADA}

Diegues, A. C. 2000. Etnoconservação da natureza: enfoques alternativos. In: Diegues, A. C. (Ed.). Etnoconservação: novos rumos para a proteção da natureza nos trópicos. Hucitec Ltda. São Paulo: p:01-46.

Ferreira, E. J. G.; J. A. S., Zuanon; G. M., Santos. 1998. Peixes comerciais do médio amazonas: região de Santarém Pará. Edições IBAMA. Brasília. 214pp.

Furtado, L.F.G. 1993. Pescadores do Rio Amazonas:um estudo antropológico da pesca ribeirinha numa área amazônica. CNPQ/MPEG. Belém. 486pp.

Goulding, M. 1983. Amazonian fisheries. In: Moran, E.F. (Ed). The dilemma of Amazonian develpment. Westview Press, Boulder. Colorado: p:189-210.

Marques, J. G. W. 1995. Pescando Pescadores: etnoecologia abrangente no baixo São Francisco. NUPAUB-USP. São Paulo. $304 \mathrm{pp}$.

Pretrere Jr, M. 1992. As comunidades humanas ribeirinhas da Amazônia e suas transformações sociais. In: Diegues, A.C. (Ed). Populações humanas, rios e mares da Amazônia. Anais do IV Encontro de Ciências Sociais e o Mar no Brasil. São Paulo: p.31-68.
Poizat, G.; E., Baran. 1997. Fishermen's knowledge as background information in tropical fish ecology: a quantitative comparison with fish sampling results. Environmental Biology of Fishes. 50: 435-449.

Santos, G. M.; M., Jegu; B., Merona. 1984. Catálogo de peixes comerciais do baixo Rio Tocantins $-1^{\circ}$ edição. Eletronorte /CNPq/INPA. Manaus - AM. 80 pp.

Veríssimo, J. 1895. A pesca na Amazônia. Livraria Clássica Alves. Rio de Janeiro. 206pp.

Zavala-Camin, L. A. 1996. Introdução ao estudo sobre a alimentação natural em peixes. EDUEM. Maringá. 129 pp. 